\title{
A novel In Vitro Model for Studying Nanoparticle Interactions with the Small Intestine
}

Christa Schimpel ${ }^{\mathrm{a}}$, Beate Rinner ${ }^{\mathrm{b}}$, Markus Absenger-Novak ${ }^{\mathrm{b}}$, Claudia Meindl ${ }^{\mathrm{b}}$, Eleonore Fröhlich ${ }^{\mathrm{b}}$, Andreas Falk $^{\mathrm{c}}$, Andreas Zimmera ${ }^{a}$ Eva Roblegg ${ }^{a, d *}$

University of Graz, Institute of Pharmaceutical Sciences, Universitätsplatz 1, Graz, Austria

Medical University of Graz, Center for Medical Research, Stiftingtalstrasse 24, Graz, Austria

BioNanoNet Forschungsgesellschaft mbH, Elisabethstraße 20/2, Graz, Austria

BioTechMed-Graz, Austria

Received 16 July 2015 accepted 14 September 2015

Abstract: Manufactured nanomaterials provide promising features for new technologies in cosmetic, food, and pharmaceutical applications. On the other hand, orally ingested nanomaterials/nanoparticles may interact with or enter intestinal cells via different mechanisms, resulting in possible injuries of the biological system. For that reason, the current study aims to provide useful information concerning physicochemical properties of nanoparticles with regard to cytotoxic effects and uptake mechanisms in the small intestine. Differently charged polystyrene nanoparticles were used and cytotoxicity and uptake were studied with an intestinal in vitro co-culture model, mimicking the villus epithelium and a triple-culture model recapitulating the follicle-associated epithelium. Mechanisms of cellular transport were investigated at $37^{\circ} \mathrm{C}$ and $4^{\circ} \mathrm{C}$ to verify that internalization mainly occurs energy-dependently. Chemical inhibitors (i.e., chlorpromazine, genistein, dynasore) were used to block dynamin-dependent endocytic pathways without affecting cell viability and membrane integrity. Qualification and quantification were performed via confocal microscopy and flow cytometry. Furthermore, co-localization studies with commonly used markers (i.e., transferrin, lactosylceramide) were carried out and co-localization was assessed via calculation of Pearson's correlation coefficient and Mander's overlap coefficient. The results show that size and surface chemistry play a crucial role in cytotoxic interactions and cellular uptake of nanoparticles (NPs). Independent of the surface charge, NPs strongly interact with intestinal mucus and are immobilized. Uptake predominantly occurs via M cells and is surface-charge dependent. Whereas negatively charged particles fail to enter cells, positive and neutral particles penetrate M cells energy-dependently. More precisely, both clathrin- and caveolae-mediated endocytosis are involved. It can be concluded that the presented system serves as a valuable tool to assess safety aspects of manufactured nanomaterials and hence, substantially contributes to nanosafety efforts.

Keywords: Caco-2 cells, goblet cells, M cells, polystyrenenanoparticles, cytotoxicity, uptake mechanism

${ }^{*}$ Corresponding author: Roblegg Eva Karl Franzens University of Graz, Institute of Pharmaceutical Sciences/Pharmaceutical Technology, Universitätsplatz 1, 8010 Graz, Austria,e-mail: eva.roblegg@uni-graz.at

\section{Introduction}

The development of engineered nanomaterials and their marketing for application in food and consumer products, medical and diagnostic devices, as well as pharmaceutical drug delivery systems has increased significantly in recent years. During the use of these products/devices, nanomaterials intended to or may accidentally get into the oral cavity, are swallowed, and end up in the gastrointestinal tract (GIT). The GIT is a complex system, comprising various kinds of epithelia. The small intestine is thrown into folds, also referred to as villi and crypts, which increase the total surface area to $300-400 \mathrm{~m}^{2}$ (Keita, 2010). Each villus contains enterocytes and mucus-secreting goblet cells, which form a firmly attached mucoid layer that protects the underlying tissue against microorganisms and pathogens (Froehlich, 2014). Thus, in many cases, if nanoparticles (NPs) end up in the small intestine, they interact with mucus (via size filtering and/or interaction filtering effects) (Sigurdsson, 2013), are wrapped up and, as a consequence, cleared from the body. However, apart from the villus-epithelium, the follicle-associated epithelium (FAE) can be found. The FAE comprises membraneous cells ( $M$ cells), located at the interface between the luminal environment and the gutassociated lymphoid tissue (Jang, 2004). They are covered with a thin layer of mucus, belong to the immune system and deliver a broad range of materials (e.g., bacteria, viruses, antigens) via transepithelial transport from the intestinal lumen directly to the underlying lymphoid tissues (Kerneis, 2000). Recently, it was shown that NP uptake in the small intestine predominantly occurs via M cells (Mahler, 2012; Antunes, 2013; Schimpel, 2014).

Basically, NPs can enter cells via passive or active mechanisms. Regarding the latter one, phagocytic and nonphagocytic pathways are involved. Unlike phagocytosis, which is restricted to specialized cells, other endocytic pathways occur in practically all cells by four energydependent main mechanisms: (i) clathrin-mediated endocytosis (CME), (ii) caveolae-mediated endocytosis (CvME), (iii) macropinocytosis (MP) and (iv) other clathrinand caveolae-independent endocytic pathways (Conner, 2003; Hillaireau, 2009). CME is the most extensively studied pathway and implicates the engulfment of receptors associated with their ligands to a coated pit. Coated pit formation occurs due to polymerization of the cytosolic 
protein clathrin. The assembled vesicle $(\sim 120 \mathrm{~nm})$ is pinched off from the plasma membrane by the small guanine triphosphatase dynamin (GTPase) and the clathrin coat is shed off. The vesicles fuse with the early endosomes, and finally primary lysosomes, which contain digestive enzymes, resulting in a degradative pathway (Kirchhausen, 2000; Takei, 2001; Rappoport, 2008; Doherty, 2009; Sahay, 2010). On the contrary, uptake can take place via caveolae $(50-70 \mathrm{~nm}$ flask shaped invaginations at the plasma membrane coated with caveolin-1), resulting in caveosomes, which do not fuse with endosomes and thus, lysosomal degradation is prevented (Pelkmans, 2001; Pietiainen, 2004; Canton, 2012). The third endocytic pathway known to be involved in NP uptake is MP (non-selective). MP occurs via membrane protrusions, forming macropinosomes (size $<1 \mu \mathrm{m}$ ), which acidify and shrink or are recycled (Hillaireau, 2009). Finally, NPs may enter cells via passive diffusion (energy-independent) and can be found freely distributed in the cytoplasm (Porter, 2007; Carney, 2012).

However, it remains uncertain, which pathways are involved in the internalization of NPs via M cells and whether surface properties (such as the surface charge) significantly impact the uptake mechanism.

\section{Methods}

2.1 Preparation of the in vitro co- and triple-culture permeability models

Caco-2 cells (ACC169, HTB-37 clone from the German Collection of Microorganisms and Cell Cultures) were cultivated at $37^{\circ} \mathrm{C}$ under $10 \% \mathrm{CO}_{2}$ and water saturated atmosphere in complete medium consisting of Dulbecco's Modified Eagle Medium (DMEM) supplemented with $10 \%$ fetal bovine serum (FBS) (Invitrogen $\mathrm{GmbH}$, Darmstadt, Germany), 1\% nonessential amino acids (NEAA) (Invitrogen $\mathrm{GmbH}$, Darmstadt, Germany), 1\% L-glutamine (Invitrogen $\mathrm{GmbH}$, Darmstadt, Germany) and $1 \%$ penicillin and streptomycin (PenStrep) (Invitrogen $\mathrm{GmbH}$, Darmstadt, Germany) according to the protocol of des Rieux et al. (des Rieux, 2007). HT29-MTX cells were kindly provided by T. Lesuffleur (INSERM UMR S 938, Paris, France) and were grown in the same medium under a humidified atmosphere (Lesuffleur, 1993). Raji B cells were a kind gift from R. Fuchs (Medical University of Graz, Austria). Raji B cells were grown in RPMI 1640 medium supplemented with $10 \%$ FBS, $1 \%$ NEAA, 1\% L-glutamine, and 1\% PenStrep at $37^{\circ} \mathrm{C}$ in a humidified $5 \% \mathrm{CO}_{2}$ atmosphere. Cells were cultured as previously described (Schimpel, 2014).

For experimental studies with the triple-culture model (Caco2/HT29-MTX/Raji B triple culture), Caco-2 and HT29-MTX were seeded at a density of $4 \times 10^{4}$ cells/per well at a ratio of 7:3 Caco-2:HT29-MTX onto 24-well culture plates (for flow cytometric analysis) and WillCo-dishes $₫$ (for confocal uptake visualization of intracellular particles). After 15 days, $1 \times 10^{6}$ Raji cells/per well were added basolaterally to the co-culture and incubated for additional 4 days ( $100 \mu$ l of culture medium replaced every day). Raji $B$ cells were removed immediately before NP transport studies. The model was compared with the co-culture comprising Caco-2 and HT29-MTX cells.

\subsection{Histochemical characterization of $\mathrm{M}$ cells and mucus}

$M$ cells were identified with wheat germ agglutinin (WGA) staining following previously described protocols (Schimpel, 2014) and the samples were observed using fluorescence microscopy (Zeiss LSM 510 META) at $488 \mathrm{~nm}$ excitation wavelength using a $505 / 550 \mathrm{~nm}$ band pass detection (BP) for the green channel and 405 excitation wavelength in conjunction with BP 420/80 for the blue spectral region. Moreover, $M$ cells show a down-regulation of the brush border enzyme alkaline phosphatase (ALP) compared with Caco-2 cells, thus, ALP activity was determined by using SIGMAFAST ${ }^{\mathrm{TM}}$ p-Nitrophenylphosphate tablets (Sigma Aldrich, Munich, Germany) according to the manufacturer's instructions. The rates of absorbance ( $M$ cells versus enterocytes), which are directly proportional to the ALP enzyme activity were determined at $405 \mathrm{~nm}$ and quantification was conducted with a VIS-plate reader (FLUOstar Optima, BMG, Labortechnik). In order to provide evidence of mucus and mucus-secreting goblet cells, Alcian Blue staining was performed. Briefly, cells were placed in $3 \%$ acetic acid for $3 \mathrm{~min}$, followed by staining with Alcian Blue solution ( $1 \mathrm{~g}$ Alcian Blue $8 \mathrm{GX}$ in $100 \mathrm{ml} 3 \%$ acetic acid). After $30 \mathrm{~min}$ of incubation at room temperature, cells were extensively washed twice with distilled water. Finally, cells were visualized by light microscopy (Olympus BX-51, camera: DP-71).

\subsection{Particle characterization}

Particle dispersions of $50 \mathrm{~nm}$ green fluorescence-labeled plain polystyrene (441/486) (50 nm PP), $200 \mathrm{~nm}$ red fluorescence-labeled plain polystyrene (542/612) $(200 \mathrm{~nm}$ PP) particles (Fisher Scientific, Vienna, Austria), $200 \mathrm{~nm}$ red fluorescence-labeled aminated (542/612) (200 nm AP) particles (Molecular Probes, Vienna, Austria) and $20 \mathrm{~nm}$ and $200 \mathrm{~nm}$ red fluorescence-labeled carboxylated $(20 \mathrm{~nm} \mathrm{CP}$, $200 \mathrm{~nm} \mathrm{CP}$ ) particles (Molecular Probes, Vienna, Austria) at a concentration of less than $1 \mathrm{mg} / \mathrm{ml}$ were prepared to determine the mean particle size and the zeta potential. The particles were suspended in MilliQ water, serumfree DMEM and phosphate-buffered saline (PBS) and ultrasonicated for $10 \mathrm{~min}$. Particle size was measured via 
photon correlation spectroscopy (PCS, Malvern Zetasizer, Malvern Instruments, Malvern, UK) equipped with a $532 \mathrm{~nm}$ laser. The zeta potential was measured by laser Doppler velocimetry (scattering angle of $17^{\circ}$ ) coupled with PCS (Zetasizer Nano ZS, Malvern Instruments) and calculated from the electrophoretic mobility by applying the Henry equation.

\subsection{Cytotoxicity study and LDH release assay}

To evaluate whether polystyrene NPs are harmful to the M-cell model, studies on the mitochondrial activity and on the cell membrane were performed in a similar manner as described earlier in literature (Teubl, 2013). For this, a CellTiter 96 aqueous non-radioactive cell proliferation assay (Promega $\mathrm{GmbH}$, Mannheim, Germany) was used. In the presence of the electron coupling reagent phenazine methosulfate (PMS) the tetrazolium compound (3-(4,5-dimethylthiazol-2-yl)-5-(3carboxymethoxyphenyl)- 2-(4-sulfophenyl)-2H-tetrazolium; MTS) is bioreduced by cells into a colored formazan product that is soluble in tissue culture medium. Cell membrane integrity was studied using CytoTox-ONE homogeneous membrane integrity assay (Promega $\mathrm{GmbH}$, Mannheim, Germany). Caco-2 and HT29-MTX were seeded in a 96 well plate at a density of $2 \times 10^{4}$ cells at a ratio of 7:3 (Caco-2:HT29MTX) and were cultured for 15 days. Next, Raji B cells were added and cultures were incubated for 4 days. Subsequently, the medium was replaced with PP50, PP200, CP20, CP200, AP200 particles/serum-free medium (SFM) dispersions in different concentrations (i.e., 10, 50, 100, 150, and $200 \mu \mathrm{g} / \mathrm{ml}$, $\mathrm{n}=3$ ) and incubated for $4 \mathrm{~h} .20 \mu \mathrm{l}$ of a MTS/PMS solution per well were added and resuspended. After an incubation time of $4 \mathrm{~h}$, the absorbance was measured at $490 \mathrm{~nm}$ with a VIS-plate reader (FLUOstar Optima, BMG, Labortechnik, Offenburg, Germany).

Briefly, for the lactatdehydrogenase (LDH) leakage assay control wells $(100 \% \mathrm{LDH}$ release) were treated with $2 \mu \mathrm{l}$ of lysis solution. $25 \mu \mathrm{l}$ of the supernatant were mixed with $25 \mu \mathrm{l}$ of the CytoTox-ONE Reagent in a white microplate. After incubation, the fluorescence was recorded at an excitation wavelength of $560 \mathrm{~nm}$ and an emission wavelength of $590 \mathrm{~nm}$. After subtraction of blank value, the average fluorescence from the samples was normalized to the maximum LDH release (lysis control). To detect possible interferences of NPs with the MTS or LDH assay (e.g., binding of assay components, interference due to fluorescence or absorbance of NP at the same wavelength of the assay dye), interference controls (blank samples containing no cells but treated exactly the same way with NP or cell lysis buffer) were run in parallel on the same 96-well plate as recommended by Rösslein et al. (Roesslein, 2014).

\subsection{Cellular uptake/quantification of NPs}

Uptake of polystyrene NPs was assessed via confocal laser scanning microscopy (CLSM) and flow cytometry (FACS). For CLSM imaging, the co-culture and the triple culture were grown on WillCo-dishes $\circledast$ at a density of $4 \times 10^{4}$ and incubated at $37^{\circ} \mathrm{C}$ for $4 \mathrm{~h}$ with $100 \mu \mathrm{g} / \mathrm{ml} \mathrm{NPs}$. After incubation, cell nuclei were stained with Hoechst 33342 (Invitrogen, $\mathrm{GmbH}$, Darmstadt, Germany). Subsequently, cells were fixed with $4 \%$ formalin in PBS and CLSM (Zeiss LSM 510 META) equipped with ZEN software package (Zeiss Germany) was performed. Red fluorescence-labeled $200 \mathrm{~nm}$ NPs were detected at 543 $\mathrm{nm}$ excitation wavelength using a LP $560 \mathrm{~nm}$ BP detection for the red channel, whereas $405 \mathrm{~nm}$ excitation wavelength in conjunction with BP $420 / 480 \mathrm{~nm}$ was used for detecting Hoechst 33342. WGA-stained cell borders were visualized at $488 \mathrm{~nm}$ laser excitation using a BP 505/550 nm BP detection for the green spectral region. The intensity of the laser beam and the photo detector sensitivity were kept constant to compare the relative fluorescence intensities between the experiments. NP uptake was analyzed using CLSM images from randomly chosen areas of the cell monolayers and images were captured with z-stack to record a three-dimensional data set.

Flow cytometric analysis was used to quantify the amount of NP uptake. The co-culture model (Caco-2/goblet cells) and the triple-culture model (Caco-2/goblet cells/M cells) were grown on 24-well plates at a density of $4 \times 10^{4} / \mathrm{per}$ well and incubated with $100 \mu \mathrm{g} / \mathrm{ml}$ red fluorescence-labeled polystyrene NPs for $4 \mathrm{~h}$ at $37^{\circ} \mathrm{C}$. After removal of the medium, the cells were washed three times with PBS. Next, cells were trypsinized to obtain a single-cell suspension, centrifuged, and cell pellets were resuspended in PBS. Finally, samples were counterstained with the dead-cell indicator SYTOX® Blue (Invitrogen $\mathrm{GmbH}$, Darmstadt, Germany), which is a high-affinity nucleic acid stain that only penetrates cells with compromised plasma membranes. To calculate the background fluorescence, untreated cells were used as negative control.

Samples treated with NPs were subsequently analyzed by FACS LSRII (BD Biosciences, San Diego, US) to determine the internalized NP concentration. Viable cells (SYTOX® Blue stained-negative cells) were gated using the 525/50 channel. The results were reported as the mean fluorescence obtained by measuring 10,000 events, averaged between 3 independent replicas of 3 independent experiments.

\subsection{In vitro cytotoxicity of endocytic inhibitors}

To examine the most efficient concentrations of the distinct endocytic inhibitors without affecting cell viability, a CellTiter 96 aqueous non-radioactive cell proliferation assay (Promega 
$\mathrm{GmbH}$, Mannheim, Germany) was carried out similarly as described previously (Teubl, 2013). Cells were seeded into a 96well microplate as described before. Medium was replaced by medium containing endocytic inhibitors at various concentrations, which ranged from 33 to $140 \mu \mathrm{M}$ for chlorpromazine, 60 to 150 $\mu \mathrm{M}$ for dynasore, and 200 to $700 \mu \mathrm{M}$ for genistein. Cells were incubated for $4 \mathrm{~h} 40 \mathrm{~min}$ at $37^{\circ} \mathrm{C}$ in a humidified atmosphere. After the incubation period, negative controls were prepared by the addition of $2 \mu$ lysis solution to wells containing cells only. Next, the MTS assay solution was added into each well and cells were incubated for another $4 \mathrm{~h}$ at $37^{\circ} \mathrm{C}$ in a humidified atmosphere. The optical density at $492 \mathrm{~nm}$ was measured by using a VISplate reader (FLUOstar Optima, BMG, Labortechnik, Offenburg, Germany). The viability of the cells exposed to pharmacological inhibitors was expressed as a percentage of the viability of cells grown in absence of inhibitors (i.e., 100\% viable control). Cell viability greater than $80 \%$ was classified as acceptable for NP uptake experiments.

To evaluate possible negative effects on the cell membrane, a LDH assay was performed. Cells were seeded as described, the medium was replaced by the endocytic inhibitors/serum-free medium dispersions and incubated for $4 \mathrm{~h} 40 \mathrm{~min}$. LDH leakage was determined using a CytoTox-ONE homogeneous membrane integrity assay (Promega $\mathrm{GmbH}$, Mannheim, Germany) according to the manufacturer's specifications. Control wells (100\% LDH release) were treated with $2 \mu \mathrm{l}$ of lysis solution. The supernatant $(25 \mu \mathrm{l})$ was mixed with $25 \mu$ of the CytoTox-ONE Reagent in a white microplate. After 10 min of incubation (at RT), the reaction was stopped by adding $12.5 \mu$ of stop solution. The fluorescence was recorded by fluorometer (FLUOstar Optima, BMG, Labortechnik, Offenburg, Germany) at $560 \mathrm{~nm}$ excitation wavelength and $590 \mathrm{~nm}$ emission wavelength. The measured fluorescence intensity produced was proportional to the number of lysed cells. LDH release from cells lysed with lysis solution was defined as $100 \%$ leakage, and LDH release from untreated cells as $0 \%$ leakage. LDH leakage below $5 \%$ was classified as suitable for NP uptake studies.

\subsection{Endocytic inhibitor studies}

To show that the inhibitor only affects the endocytic pathway of interest, transferrin was co-incubated with chlorpromazine $(70 \mu \mathrm{M})$ and Lactosylceramide (LacCer) with genistein $(300 \mu \mathrm{M})$. Cells solely treated with transferrin and LacCer were utilized as positive controls. Subsequently, endocytic pathways involved in polystyrene NP uptake were investigated. For this, pharmacological inhibitors (Sigma Aldrich, Munich, Germany) that prohibit specific cellular uptake pathways were used at appropriate concentrations (see Table 1).

Cells were grown on 24-well culture plates/WillCo-dishes ${ }^{\circledR}$ (confocal and FACS, respectively) at a density of $4 \times 10^{4}$. Triple cultures were pre-incubated (40 $\mathrm{min}$ ) with pharmacological endocytic inhibitors, followed by the addition of fluorescencelabeled NPs (100 $\mu \mathrm{g} / \mathrm{ml}$; incubation $4 \mathrm{~h}$ ). Cells solely treated with NPs were utilized as positive control. First, inhibition of both CME and CvME was conducted with the dynaminGTPase inhibitor dynasore $(90 \mu \mathrm{M})$ to evaluate whether MP or other dynamin-dependent pathways are involved. Second, $300 \mu \mathrm{M}$ genistein was used to inhibit CvME. Finally, CME was assessed utilizing treatment with $70 \mu \mathrm{M}$ chlorpromazine. Additionally, NP uptake studies were carried out at $4^{\circ} \mathrm{C}$ to determine energy-dependency of NP uptake since it has been reported that NP uptake can also occur via energyindependent processes, such as passive diffusion (Herd, 2013). All samples were visualized via CLSM.

\subsection{Co-localization studies}

To get deeper insights into the specific mechanisms involved, properly speaking to differ between CME and CVME, colocalization was studied with transferrin, a well-known marker of clathrin-mediated uptake (Rejman, 2004) and with LacCer, a caveolae-mediated endocytosis marker (Marks, 2005). For this, cells were incubated with the specific inhibitors; after that, particles were applied and transferrin $(20 \mu \mathrm{g} / \mathrm{ml})$ or LacCer $(0.5 \mu \mathrm{M})$ was added.

For CLSM imaging, nuclei were counterstained with Hoechst 33342 (Invitrogen $\mathrm{GmbH}$, Darmstadt, Germany). Red fluorescence-labeled $200 \mathrm{~nm}$ particles were detected at 543 $\mathrm{nm}$ excitation wavelength using a LP $560 \mathrm{~nm}$ BP detection for the red channel. Alexa Fluor $488 \circledR$ Transferrin and BODIPY $®$ LacCer were visualized at $488 \mathrm{~nm}$ laser excitation using a BP 505/550 nm BP detection for the green spectral region. $405 \mathrm{~nm}$ excitation wavelength in conjunction with BP 420/480

\begin{tabular}{ccc}
\hline Endocytic inhibitor & Concentration & Function \\
Dynasore & $90 \mu \mathrm{M}$ & $\begin{array}{c}\text { Inhibition of the GTPase activity of dynamin, blocks pinching-off of clathrin-and caveolin- } \\
\text { coated vesicles (Macia, 2006) }\end{array}$ \\
Genistein & $300 \mu \mathrm{M}$ & Inhibition of caveolae-mediated/lipid raft endocytosis, commonly utilized inhibitor of protein \\
tyrosine kinase (Hubbard, 2000) & Inhibitor of clathrin-mediated endocytosis by depleting the plasma membrane of clathrin and \\
adaptor proteins (Herd, 2013)
\end{tabular}

Table 1. Endocytic inhibitors used for uptake experiments 
$\mathrm{nm}$ was used for detecting Hoechst 33342. Analyses were performed with the internal ZEN quantification software. By selecting images under $488 \mathrm{~nm}$ and $560 \mathrm{~nm}$ channels as image pair, Pearson's correlation coefficient (PCC) and and Mander's overlap coefficient (MOC) were calculated from the following equations (Barlow, 2010):

$$
\begin{aligned}
& P C C=\frac{\sum\left(R_{i}-R_{\text {average }}\right) \times\left(G_{i}-G_{\text {average }}\right)}{\sqrt{\sum\left(R_{i}-R_{\text {average }}\right)^{2} \times \sum\left(G_{i}-G_{\text {average }}\right)^{2}}} \\
& M O C=\frac{\sum\left(R_{i}\right) \times\left(G_{i}\right)}{\sqrt{\sum\left(R_{i}\right)^{2} \times \sum\left(G_{i}\right)^{2}}}
\end{aligned}
$$

where $R_{i}$ represents signal intensity of pixels in red channel and $G_{i}$ represents signal intensity of pixels in green channel; $\mathrm{R} 1_{\text {average }}$ and $\mathrm{G} 1_{\text {average }}$ show the average intensities of these respective channels.

\subsection{Statistical analysis}

All experiments were performed in triplicates and the results were presented as mean \pm standard deviation. Statistical analysis (one-way analysis of variance, ANOVA) was performed. Differences were considered to be significant at a level of $p<0.05\left(^{*}\right)$ and $p<0.01\left(^{* *}\right)$.

\section{Results and Discussion}

3.1 Development and characterization of the co-and the triple-culture model

In the current study, in vitro permeability models of the villus epithelium and the FAE designated to investigate endocytic uptake mechanisms of NPs were used. For the co-culture, Caco-2 cells and mucus-secreting goblet cells (HT29-MTX) were treated on transwells. For the triple-culture model, Raji B cells were added to an enterocyte/goblet cell monolayer and differentiation into $\mathrm{M}$ cells occurred. M-cell identification was carried out with two histochemical methods. First, Alexa Fluor 488 fluorescence-labeled lectin WGA was used to selectively detect $\mathrm{N}$-acetylglucosamine and $\mathrm{N}$-acetylneuraminic acid (sialic acid) residues, which are predominantly present on M-cell surfaces. Moreover, enzyme activity of the hydrolytic enzyme ALP was determined since ALP is reduced in M cells compared with enterocytes (Nicoletti, 2000). The results clearly showed a significant increase of the green emission due to higher lectin-binding-affinity of $\mathrm{M}$ cells compared with enterocytes and goblet cells (see Figure S1, Supporting Information File 1). Additionally, ALP activity in the tripleculture model was significantly decreased $\left(12 \% ;{ }^{* *} p<0.01\right)$ compared with the control (Caco-2/goblet cells, 100\%), implying the presence of $\mathrm{M}$ cells.

Since it is known that intestinal mucus strongly impacts the mobility of NPs, staining of mucus was performed. The presence of mucus was identified on top of the triple-culture cell surface, but not on the monoculture of Caco-2 cells (see Figure S2, Supporting Information File 1).

\subsection{Physicochemical characterization and cytotoxicity of NPs}

Size, surface charge and polydispersity index (Pdl) of the particles in different media were determined via PCS (see Table 2). In MilliQ water, dispersion was best and smallest sizes were recorded. The results showed that the mean hydrodynamic diameters and the zeta potential values were not affected by the different media used, thus agglomeration

\begin{tabular}{|c|c|c|c|c|c|c|c|c|c|}
\hline & \multicolumn{3}{|c|}{$50 \mathrm{~nm}$ PP particles } & \multicolumn{3}{|c|}{$20 \mathrm{~nm}$ CP particles } & \multicolumn{3}{|c|}{$200 \mathrm{~nm}$ AP particles } \\
\hline & $d(n m)$ & $\underset{(\mathrm{mV})}{\zeta}$ & Pdl & $d(n m)$ & $\stackrel{\zeta}{\zeta}$ & Pdl & $d(n m)$ & $\stackrel{\zeta}{\zeta}$ & Pdl \\
\hline MilliQ water & $51.2 \pm 3.43$ & -15.7 & 0.036 & $31.2 \pm 2.45$ & -39.6 & 0.141 & $201.2 \pm 2.78$ & 10.5 & 0.201 \\
\hline SFM $^{*}$ & $62.9 \pm 1.22$ & -20.1 & 0.311 & $44.5 \pm 1.25$ & -31.7 & 0.164 & $222.8 \pm 2.14$ & 11.8 & 0.227 \\
\hline \multirow[t]{3}{*}{ PBS } & $57.18 \pm 1.04$ & -12.8 & 0.269 & $33.6 \pm 1.14$ & -43.2 & 0.091 & $202.4 \pm 1.78$ & 8.5 & 0.300 \\
\hline & \multicolumn{3}{|c|}{$200 \mathrm{~nm}$ PP particles } & \multicolumn{3}{|c|}{$200 \mathrm{~nm}$ CP particles } & & & \\
\hline & $\mathrm{d}(\mathrm{nm})$ & $\begin{array}{c}\zeta \\
(\mathrm{mV})\end{array}$ & Pdl & $\mathrm{d}(\mathrm{nm})$ & $\begin{array}{c}\zeta \\
((\mathrm{mV}) \\
\end{array}$ & Pdl & & & \\
\hline MilliQ water & $209.0 \pm 1.45$ & -8.7 & 0.044 & $245.1 \pm 2.8$ & -46.6 & 0.0841 & & & \\
\hline SFM $^{*}$ & $205.8 \pm 1.16$ & -17.3 & 0.103 & $304.2 \pm 1.2$ & -47.6 & 0.162 & \multicolumn{3}{|c|}{ *used for uptake studies } \\
\hline PBS & $211.8 \pm 2.94$ & -2.4 & 0.089 & $268.2 \pm 1.7$ & -28.8 & 0.158 & & & \\
\hline
\end{tabular}
could be excluded.

Table 2. Hydrodynamic diameter ( $\mathrm{nm})$, surface charge ( $\zeta$-potential) and polydispersity index (Pdl) of $50 \mathrm{~nm}$ plain polystyrene (PP) particles, $200 \mathrm{~nm}$ plain polystyrene (PP) particles, $20 \mathrm{~nm}$ carboxylated polystyrene (CP) particles, $200 \mathrm{~nm}$ carboxylated (CP) polystyrene particles, and $200 \mathrm{~nm}$ aminated polystyrene (AP) particles in MilliQ water, serum-free medium (SFM), and phosphate-buffered saline (PBS). 
It is known from the literature that NPs may cause injuries to biological systems (e.g., multi-well nanotubes, silver NPs, silica particles) (Lewinski, 2008; Napierska, 2009; Park, 2011). Due to reducing particle size from the microscale to the nanoscale, the reactivity increases (Mayer, 2009) and associated with that, adverse effects might occur. To evaluate whether polystyrene particles penetrate the cells in a destructive or non-destructive manner, cytotoxicity studies were performed with the triple-culture model (Schimpel, 2014). To exclude NP interference with the test reagents (MTS/LDH), absorbance/fluorescence investigations were performed prior to cytotoxicity tests. The results revealed that exposure to $20 \mathrm{~nm} \mathrm{CP}$ and $50 \mathrm{~nm}$ PP caused cytotoxic damage (as indicated by LDH release) and a decrease in cell survival (as determined by MTS) in a concentration-dependent manner. At $100 \mu \mathrm{g} / \mathrm{ml}$ (which corresponds to the concentration used for subsequent uptake experiments), cell viability was significantly decreased to $63.7 \%$ for $50 \mathrm{~nm}$ PP particles $\left({ }^{* *} p<0.01\right)$ and to $53.3 \%$ for $20 \mathrm{~nm}$ CP particles $\left({ }^{* *} p<0.01\right)$. Moreover, LDH release was considerably increased $(10.2 \%$ for $50 \mathrm{~nm}$ PP particles and $15.6 \%$ for $20 \mathrm{~nm} \mathrm{CP}$ particles (** $p<0.01$ ), which is consistent with data reported by Fröhlich et al. (Fröhlich, 2012). In contrast, differently charged $200 \mathrm{~nm}$ polystyrene particles showed no cytotoxic response (see Figure 1) and were, thus, used for further experiments.

\subsection{Cellular uptake/quantification using polystyrene NPs}

NPs' physicochemical properties such as size and hydrophilicity are known to be relevant parameters that impact the uptake rate (Zauner, 2001; Verma, 2010). This is also reported for the surface charge (Huang, 2002; Mao, 2005; Harush-Frenkel, 2007). Depending on the cell type, negative particles display little or no association/internalization with the cell plasma membrane of epithelial cells compared with positively charged NPs. To verify this phenomenon also for $M$ cells, mechanistic experiments considering three distinct surface charges were performed.

Evidence of particle internalization via $M$ cells was obtained by using flow cytometry. After $4 \mathrm{~h}$, all investigated NPs failed to penetrate the co-culture irrespective of the particles' surface charge. In the triple-culture model, uptake predominantly occurred via M cells. As expected, positively charged NPs as well as neutral particles were internalized by $\mathrm{M}$ cells within $4 \mathrm{~h}$. The calculated uptake rate was $26.7 \%$ ( ${ }^{* *} p<0.01$ ) for $200 \mathrm{~nm}$ PP particles and $33.2 \%\left({ }^{* *} p<0.01\right)$ for $200 \mathrm{~nm}$ AP particles, respectively (see Table 3 ). Negatively charged particles failed to enter the cell since electrostatic repulsion from anionic sites of the plasma membrane (e.g., proteoglycans) inhibits their penetration (Harush-Frenkel, 2008). Similar findings were reported by des Rieux et al. (des Rieux, 2005). They investigated

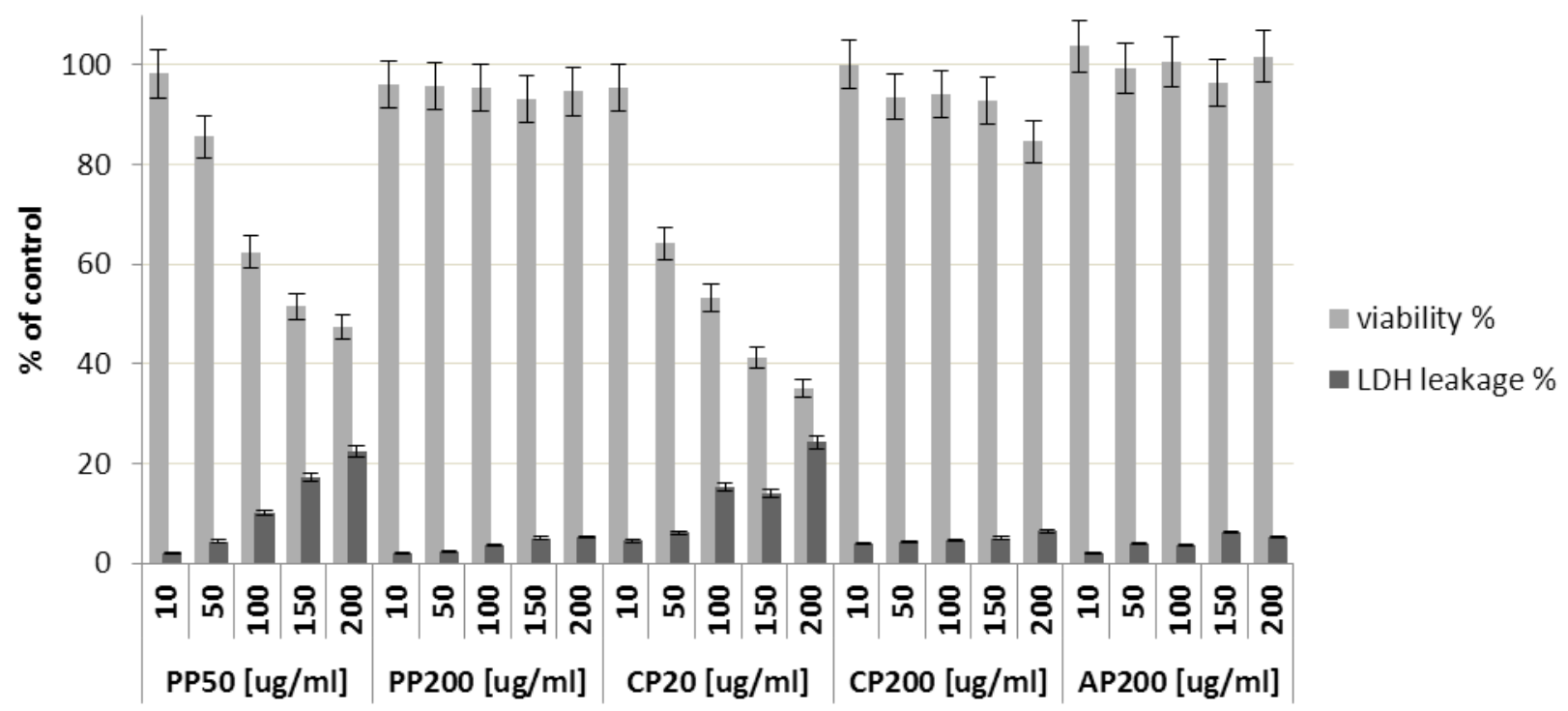

Figure 1. Cytotoxicity/lactatdehydrogenase leakage of polystyrene NPs. The graph indicates the percentage of cell viability/lactatdehydrogenase release for different concentrations of polystyrene nanoparticles. The results are reported as mean \pm standard deviation with $n=3$. 


\begin{tabular}{lccc}
\hline & \multicolumn{1}{c}{ Particle uptake [\%] } \\
\hline & $\mathbf{2 0 0} \mathbf{~ n m ~ P P ~ p a r t i c l e s ~}$ & $\mathbf{2 0 0} \mathbf{~ n m ~ A P ~ p a r t i c l e s ~}$ & $\mathbf{2 0 0} \mathbf{~ n m ~ C P ~ p a r t i c l e s ~}$ \\
$\begin{array}{c}\text { Caco-2l } \\
\text { HT29-MTX }\end{array}$ & $0.9 \pm 0.02$ & $1.2 \pm 0.01$ & $0.4 \pm 0.01$ \\
$\begin{array}{c}\text { Triple-cul- } \\
\text { ture model }\end{array}$ & $26.7 \pm 2.1$ & $33.2 \pm 2.7$ & $0.8 \pm 0.02$ \\
\hline
\end{tabular}

Table 3. Cellular uptake/internalization of $200 \mathrm{~nm}$ PP, $200 \mathrm{~nm} \mathrm{AP}$ and $200 \mathrm{~nm}$ CP particles in the co-culture and the triple-culture model

the impact of the physicochemical properties on the transport/ uptake via M-cells using $200 \mathrm{~nm}$ carboxylated or aminated latex particles. In contrast to our results, both negatively charged and positively charged particles were taken up by $\mathrm{M}$ cells. However, aminated NPs were more efficiently transported than carboxylated NPs, suggesting that the presence of cationic groups enhances NP-cell surface-adsorption, resulting in a higher uptake. Moreover, the influence of particle charge on the uptake via $\mathrm{M}$ cells was also studied in vivo. It was shown that the uptake of negatively charged polystyrene particles via murine $\mathrm{M}$ cells was significantly decreased compared with non-ionized ones (Keegan, 2003).

Additionally, to NP uptake investigations via flow cytometry, confocal microscopy was performed with the co-culture as well as with the triple-culture model. Regarding the triple- culture model, optical cross sections revealed that only neutral and positively charged particles were detected inside the cells in specific $\mathrm{M}$ cell-rich regions that were not covered with mucus (see Figure S3, Supporting Information File 1). However, in the co-culture, NPs - independent on their surface charge - were entrapped in the mucus layer and hence, failed to penetrate the underlying cells (see Figure 2). These results strongly suggest that the mucus layer presents a strong barrier for NPs, which is in agreement with findings by Crater et al. (Crater, 2010) and Behrens et al. (Behrens, 2002). Apart from that, recently published data by our group show that cell mechanics/dynamics (i.e., cell elasticity, adhesion) are also critical parameters that influence intestinal internalization/ uptake of NPs (Schimpel, 2015). M cells display a smooth, mucus-free and more elastic surface due to the absence of a

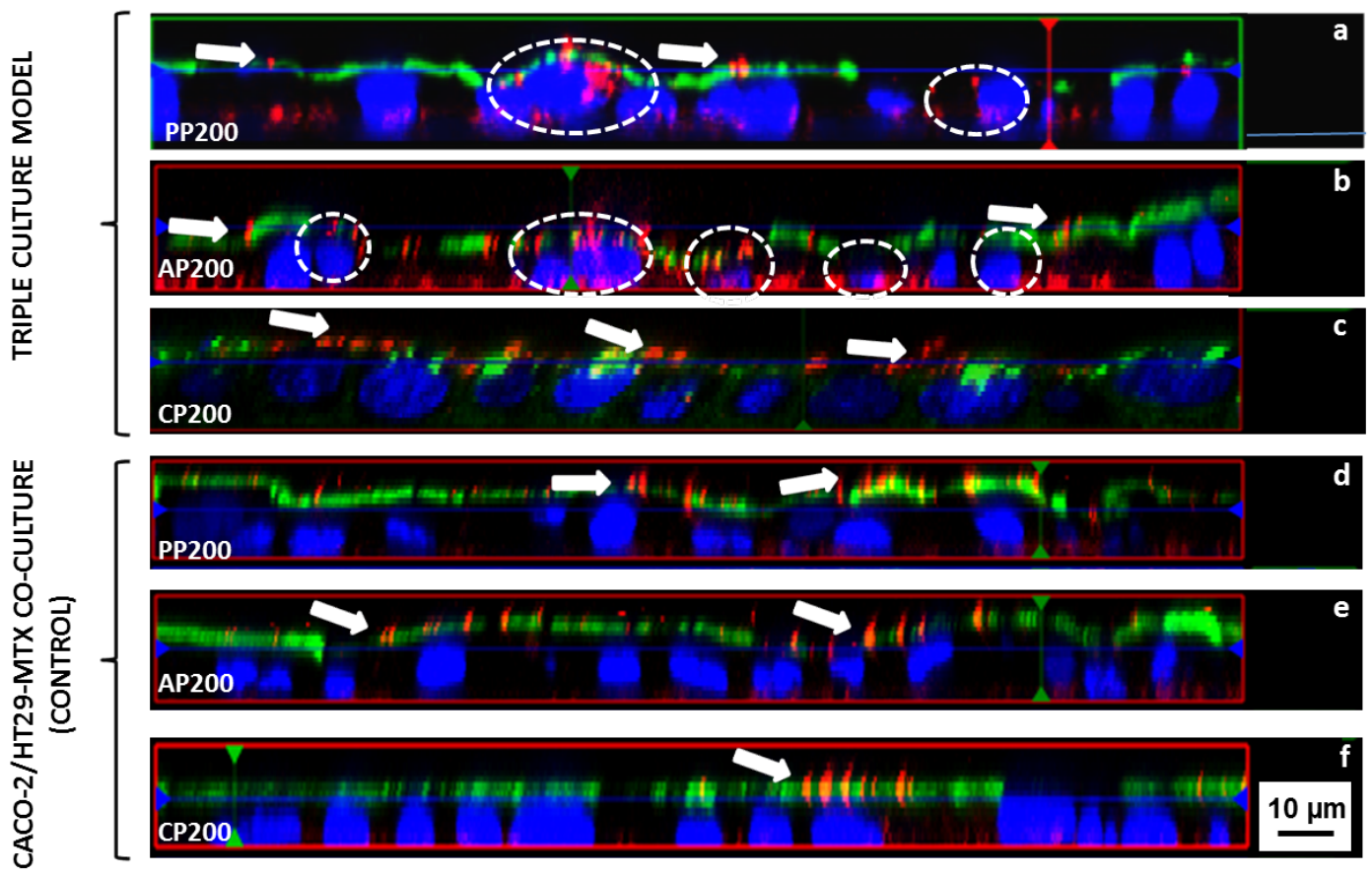

Figure 2. Fluorescence microscopic z-scans of the triple-culture model ( $a, b, c)$ and the corresponding control (co-culture) (d, e, $f$ ) treated with $200 \mathrm{~nm}$ plain polystyrene particles, $200 \mathrm{~nm}$ aminated polystyrene particles and $200 \mathrm{~nm}$ carboxylated polystyrene particles (shown in red). Cell nuclei were stained with Hoechst (blue), cell borders were stained with Alexa Fluor 488 WGA (green). The circles indicate NP uptake/penetration into $M$ cells, whereas arrows depict entrapped/immobilized particles in the mucoid layer. 
microvilli-rich intestinal brush border, leading to a significantly higher M-cell adhesion ability compared with Caco-2 cells. As a result, particles adhere to the cell surface more rapidly. Additionally, cellular uptake is facilitated due to a higher elastic deformation of the cytoskeleton, which can be attributed to the decrease of filamentous actin. As a consequence, $M$ cells show a higher bending elasticity of the cell membrane and hence promote the engulfment process of NPs.

3.4 Endocytic inhibitor studies and co-localization of polystyrene NPs

To elucidate whether the mechanism of M-cell internalization is only actively driven, cell experiments were performed at $4^{\circ} \mathrm{C}$ and at $37^{\circ} \mathrm{C}$. NP that uptake was entirely inhibited at lower temperatures (data not shown), suggesting that particle internalization via $\mathrm{M}$ cells only occurs via energy-dependent pathways, which is in accordance with findings by other groups (Kerneis, 1997; Gullberg, 2000; des Rieux, 2005). Hence, the main pathway involved in internalization of NPs is endocytosis (Sahay, 2010). Currently, the two most well characterized endocytic pathways are CME and CvME. To investigate if these routes are also dominant in M-cell uptake, we studied NP uptake in the presence of different endocytic inhibitors. For this, it is of paramount importance to assess the appropriate concentration of each inhibitor that on the one hand, does not harmfully affect cell viability and integrity and on the other hand, sufficiently inhibits the pathway of interest. Various concentrations of three frequently used inhibitors (i. e., dynasore, genistein, chlorpromazine) were tested (Rejman, 2004; Marks, 2005) and the effect on cell viability/integrity was studied. The inhibitor concentrations that revealed cell viability values $\geq 80 \%$ and LDH leakage $<5 \%$ were classified as non-toxic and selected for the uptake experiments (results presented in Table 4 and Figure 3) (Vercauteren, 2010).

Dynasore, an inhibitor that is responsible for vesicle scission during CME and CvME (Goldberg, 2010), showed a decrease of the cell viability with increasing concentrations. $90 \mu \mathrm{M}$ was found to be acceptable with a viability $>80 \%$ and LDH leakage $<2 \%$. Genistein is a tyrosine kinase inhibitor and hinders the recruitment of dynamin 2, both known to be crucial for CvME (Parton, 1994; Nabi, 2003). Genistein exhibited no significant impact on the cell integrity, however, the cell viability decreased with increasing concentrations. A concentration of $300 \mu \mathrm{M}$

\begin{tabular}{cccc}
\hline Endocytic inhibitor & Concentration & $\begin{array}{c}\text { Cell viability [\%] } \\
\text { Mean } \pm \text { SD }\end{array}$ & $\begin{array}{c}\text { LDH (\%) leakage } \\
\text { Mean } \pm \text { SD }\end{array}$ \\
\hline Dynasore & $90 \mu \mathrm{M}$ & $89.0 \pm 3.8$ & $1.8 \pm 0.4$ \\
Genistein & $300 \mu \mathrm{M}$ & $88.5 \pm 2.7$ & $4.8 \pm 2.9$ \\
Chlorpromazine & $70 \mu \mathrm{M}$ & $81.79 \pm 2.4$ & $3.6 \pm 0.9$ \\
\hline
\end{tabular}

Table 4. Cell viability/lactatdehydrogenase leakage of endocytic inhibitors

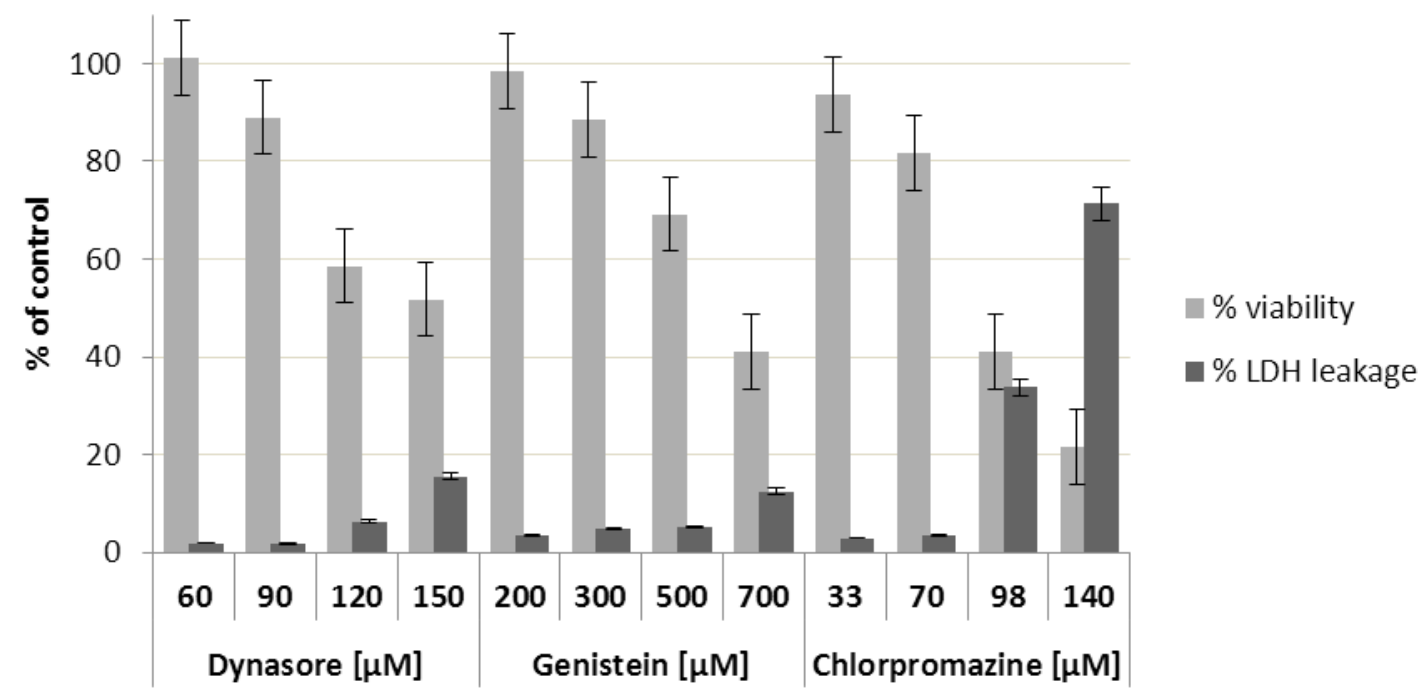

Figure 3. Cytotoxicity/lactatdehydrogenase leakage of endocytic inhibitors. Cells were incubated for $4 \mathrm{~h} 40 \mathrm{~min}$ at $37^{\circ} \mathrm{C}$ with 3 endocytic inhibitors. The graph indicates the percentage of cell viability/LDH release for the different concentrations for each endocytic inhibitor. Results were reported as mean \pm standard deviation with $n=6$. 
was found to be appropriate for subsequent experiments. Chlorpromazine, which inhibits clathrin-coated pit formation by a reversible translocation of clathrin and its adaptor proteins from the plasma membrane to intracellular vesicles (Wang, 1993; Vercauteren, 2010), was used at a concentration of $70 \mu \mathrm{M}$.

Next, we evaluated the specificity of the inhibitors by coincubating transferrin with chlorpromazine $(70 \mu \mathrm{M})$ and LacCer with genistein $(300 \mu \mathrm{M})$. Based on flow cytometry data, both inhibitors showed specific inhibition of transported transferrin and LacCer (i.e., CME and CvME) under experimental conditions (see Figure S4, Supporting Information File 1). Thus, the appropriate concentrations of the inhibitors were used to study specific endocytic pathways involved in NP uptake. Cells were incubated with each inhibitor and positively charged and neutral NPs were added. The results showed that all inhibitors significantly decreased the uptake of $200 \mathrm{~nm}$ $\mathrm{PP}$ and $200 \mathrm{~nm}$ AP particles (see Figure 4). Incubation with dynasore, which is essential to inhibit CME and CvME, resulted in a marked decrease in the cellular uptake $(90 \%$ compared with the positive control; $\left.{ }^{* *} p<0.01\right)$. This indicates that MP and other pathways are likely to be involved to a minor extent, however, NP uptake predominantly occurs via CME and/or CvME. To differ and identify the main pathway involved, experiments were conducted with chlorpromazine

A

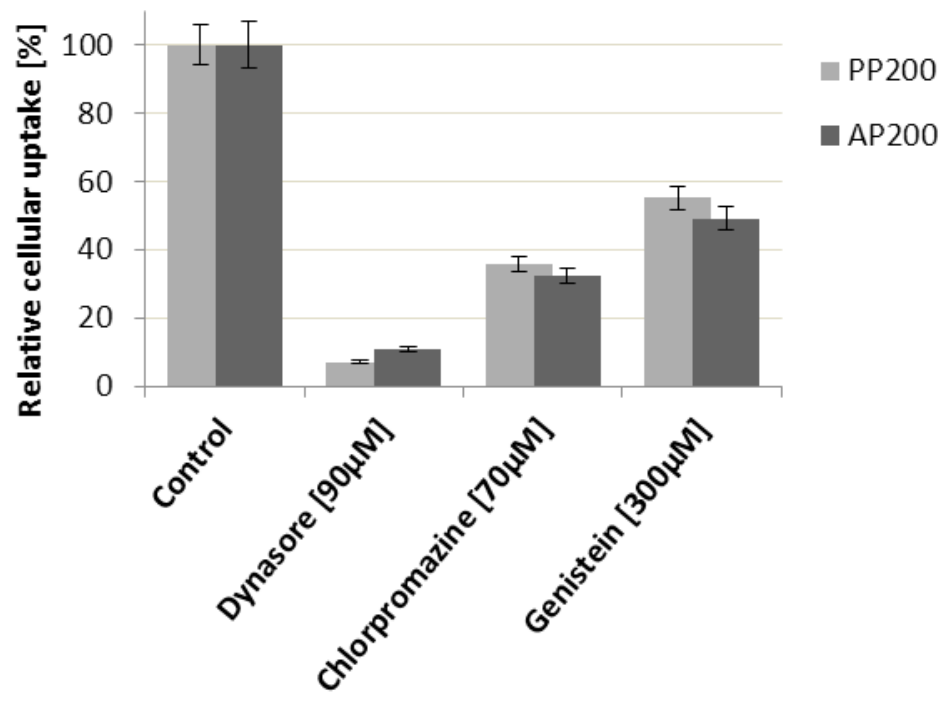

B
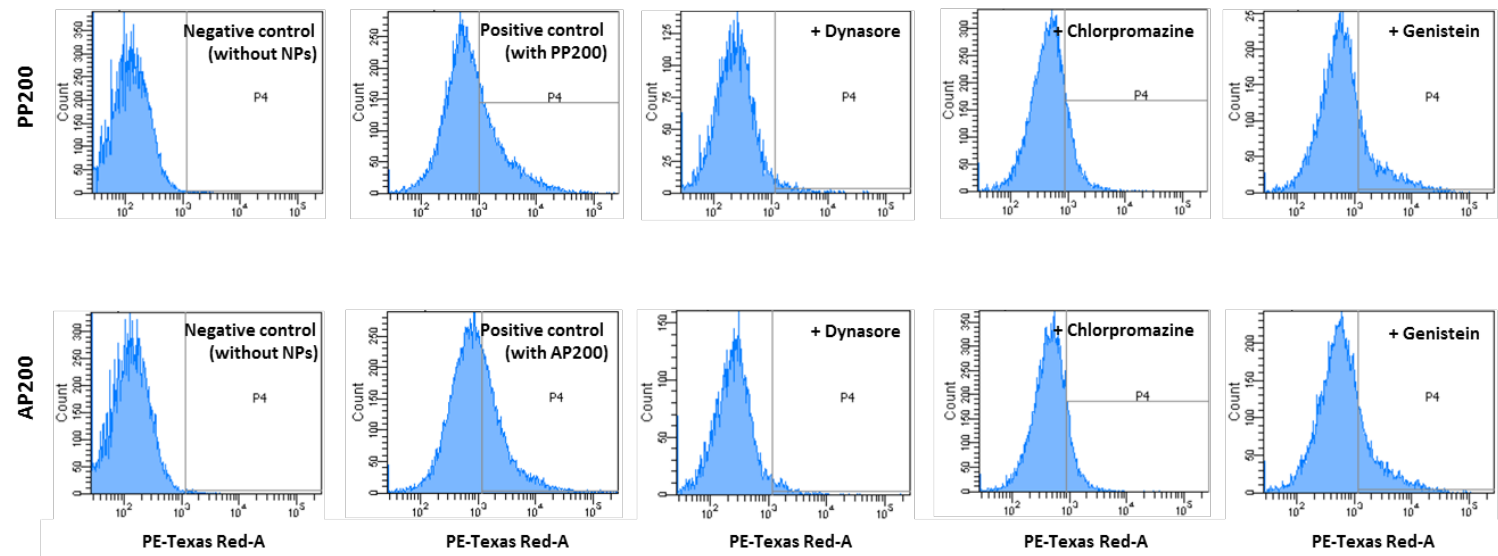

Figure 4. A: Influence of different endocytic inhibitors on cellular uptake of $200 \mathrm{~nm}$ plain polystyrene particles and $200 \mathrm{~nm}$ aminated polystyrene particles in the triple-culture model. B: Flow cytometry histograms; untreated cells were used as negative control and nanoparticles treated cells without inhibitors as positive control. Other values were compared to the control using analysis of variance $\left({ }^{*} p<0.05,{ }^{* *} p<0.01\right.$, $\left.{ }^{* * *} p<0.005\right)$. 
to inhibit CME. The calculated values clearly showed that the uptake was significantly reduced independent of the surface charge (i. e., $64.4 \%$ and $67.8 \%$ for PP $200 \mathrm{~nm}$ and AP $200 \mathrm{~nm}$ compared with the control; $\left.{ }^{* *} \mathrm{p}<0.01\right)$. Treatment with genistein, used to hinder CvME, significantly decreased the uptake of NPs $(44.9 \%$ and $50.9 \%$ for PP $200 \mathrm{~nm}$ and AP $200 \mathrm{~nm}$ compared with the control; $\left.{ }^{* *} p<0.05\right)$. This implies that NP uptake via M cells is non-specific, more precisely that both CME as well as lipid raft/CvME are involved in the uptake of $200 \mathrm{~nm}$ polystyrene particles. He et al. (He, 2013) showed that the uptake of $80 \mathrm{~nm}$ polymeric NP in Caco-2 cells also occurs via non-specific endocytic mechanisms (i.e., $35 \%$ clathrin-dependent uptake, $50 \%$ caveolae-mediated endocytosis and $50 \%$ macropinocytosis). However, uptake of $200 \mathrm{~nm}$ carboxylated polystyrene NPs by M cells is reported to mainly occur by the transcellular route, predominantly via macropinocytosis (des Rieux, 2007). In contrast, our results indicate that uptake of positively and neutrally charged NP via
$M$ cells dominantly occurs via CME and CvME. This suggests that NP surface charge is likely to influence the uptake mechanisms via $\mathrm{M}$ cells.

Due to electrostatic interactions between NPs and the cell plasma membrane, the usage of flow cytometry as analytical tool to reveal cellular uptake is sometimes difficult and has to be verified. One convenient way to conclude that the decrease in particle uptake in the presence of endocytic inhibitors simply arises due to their inhibiting effects (and that NPs are not just bound on the cell surface), is to perform colocalization studies with commonly used fluorescent-labeled intracellular endocytic markers, such as transferrin and/or LacCer. However, recently, it was reported that the efficacy of these markers is cell line dependent (Vercauteren, 2010). In this study, the triple-culture model was treated with NPs and transferrin or LacCer. The z-stacks clearly showed that without the addition of endocytic inhibitors, transferrin and LacCer were internalized by the cells (Figure 5). NPs were
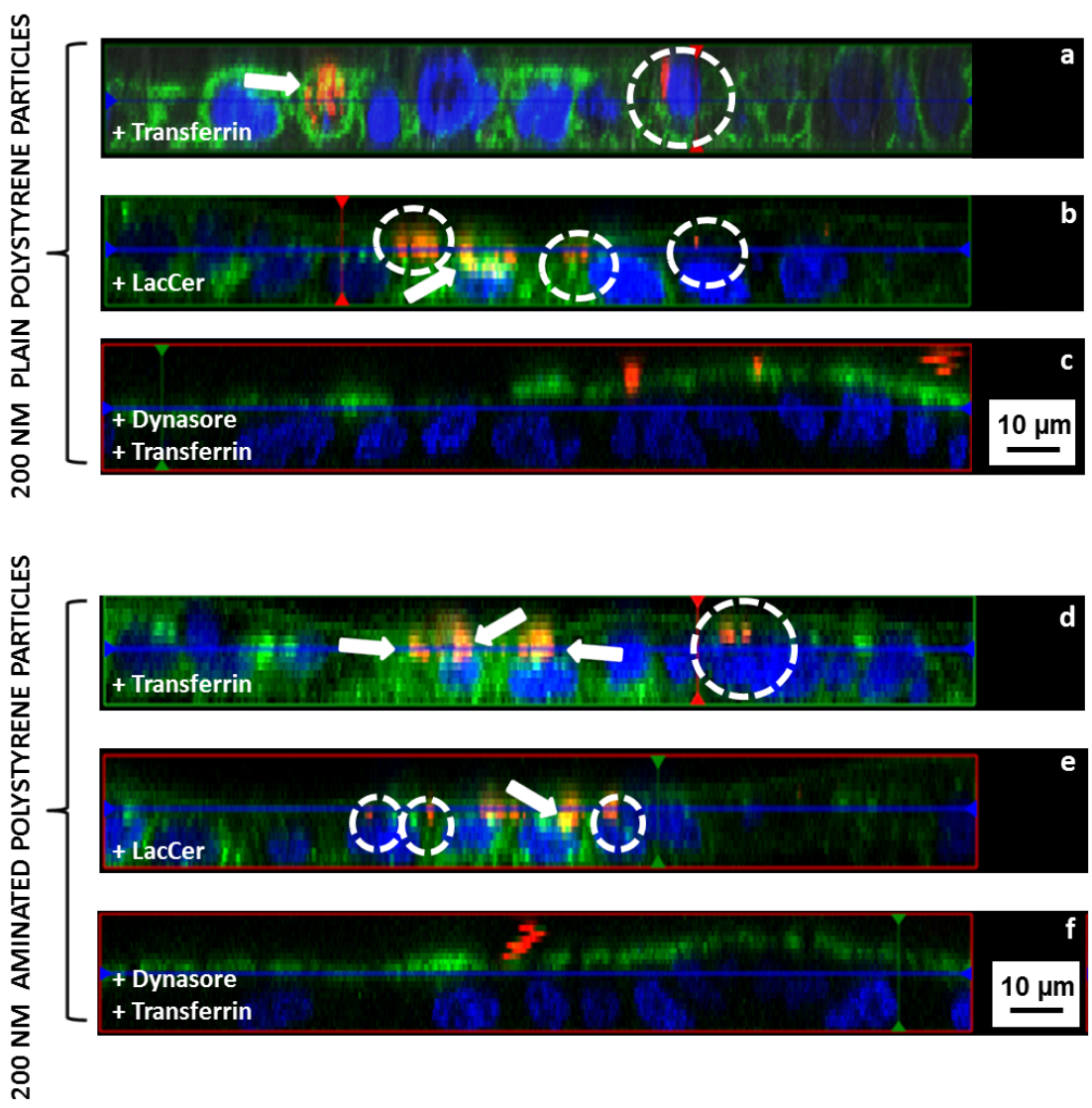

Figure 5. Fluorescence microscopic z-scans of the triple-culture model treated with $200 \mathrm{~nm}$ plain polystyrene particles and $200 \mathrm{~nm}$ aminated polystyrene particles (shown in red) in the presence of endocytic inhibitors. Cell nuclei were stained with Hoechst (blue), endocytic markers (i.e., transferrin and LacCer) were depicted in green. The circles indicate nanoparticle uptake/penetration, whereas arrows reveal numerous yellow spots indicating the co-localization of internalized particles with transferrin $(a, d)$ and LacCer (b, e). 
detected as yellow spots in M cells (due to the overlap of green and red fluorescence) indicating co-localization with either transferrin or LacCer. The addition of dynasore entirely inhibited the uptake of both markers.

To quantify these results, co-localization was calculated by using PCC and MOC. PCC is a standard measure in pattern recognition to assess co-localization by means of describing the relationship/correlation of two fluorescent intensity distributions from two images (Zinchuk, 2008). It generates a range of values from +1 , indicating a perfect positive correlation (i.e., all pixels are in straight line in the scatter diagram), to -1 , a perfect but inverse correlation. Zero represents a random distribution representing no colocalization (i.e., pixels in scattergram distribute in a cloud with no preferential direction). The PCCs are classified from 0.5 to 1.0 , indicating co-localization and from -1.0 to 0.5 , indicating absence of co-localization. MOC is a co-localization coefficient that is insensitive to the limitations of fluorescence imaging, like photobleaching or camera quantum efficiency, just to mention two examples (Manders, 1993). MOC generates only positive values, thus, direct interpretation regarding the degree of overlap is possible. These values are in the range from 0 to 1.0. For example, an overlap coefficient of 0.75 reveals that $75 \%$ of its both objects (i.e., pixels) overlap and three-quarters co-localization occurs - compared with zero, meaning no co-localization. Classification ranges from 0.6 to 1.0 , indicating co-localization and from 0 to 0.6 , revealing absence of co-localization.

The results are presented graphically in scatterplots (Figure $6 \mathrm{~A})$. The intensity of green colored transferrin and LacCer were plotted against the intensity of red-labeled polystyrene particles. Co-localizing pixels are shown in scatter region 3. In contrast, the lack of co-localization is reflected by the distribution of points into two separate groups, that is, scatter region 1 and 2. Co-localization of endocytic markers and NPs was apparent as yellow spots due to the overlay of green and red fluorescence.

All data from the co-localization coefficients are summarized in Figure 6B. The results revealed that for $200 \mathrm{~nm}$ PP particles, the calculated PCC was 0.66 , indicating co-localization of the $\mathrm{NPs}$ with transferrin. The MOC value was 0.85 , meaning an overlap of $85 \%$. The degree of co-localization for LacCer was found to be lower, with an estimated PCC of 0.58 and MOC of 0.7 . These results suggest that CvME is involved in PP
A
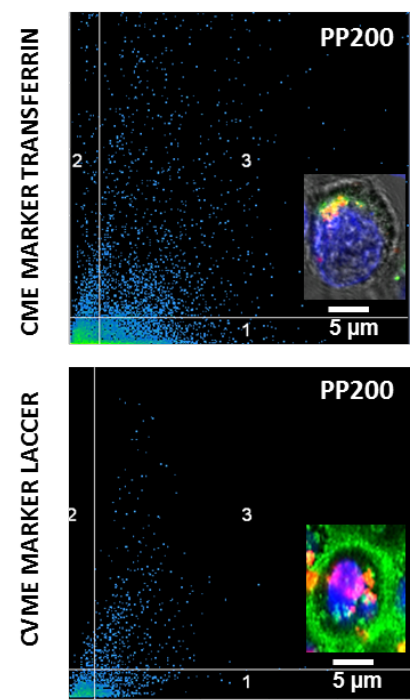
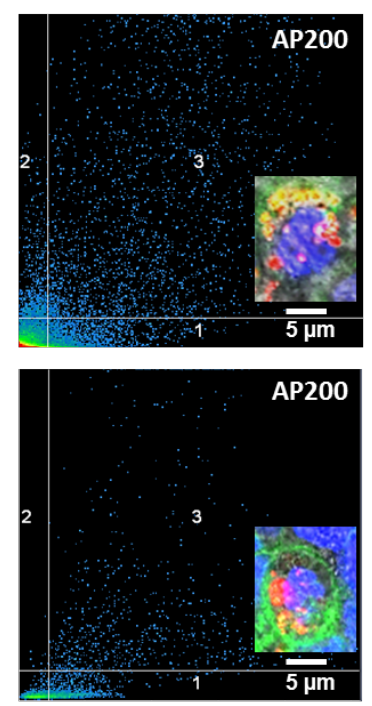

B

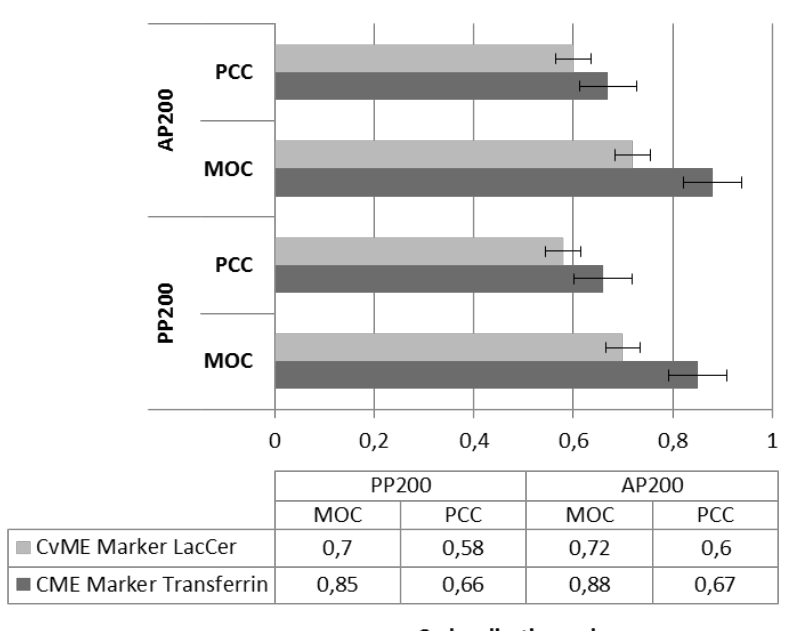

Co-localization values

Figure 6. Intracellular trafficking of $200 \mathrm{~nm}$ plain polystyrene particles and $200 \mathrm{~nm}$ aminated polystyrene particles. A: Co-localization images and scatterplots of $200 \mathrm{~nm}$ plain polystyrene particles and $200 \mathrm{~nm}$ aminated polystyrene particles with CME marker transferrin and CvME marker LacCer after $4 \mathrm{~h}$. Yellow fluorescence spots displayed the co-localization of NPs with transferrin and LacCer in merged images. B: Comparison of quantitative co-localization of $200 \mathrm{~nm}$ plain polystyrene particles and $200 \mathrm{~nm}$ aminated polystyrene particles with CME and CVME marker by examining Pearson's correlation coefficient (PCC) and Mander's overlap coefficient (MOC). 
particle uptake, but less than CME. Regarding $200 \mathrm{~nm}$ AP particles, similar values were obtained. For all calculations background correction in the region, which was used for calculation of the correlation coefficients, was performed. This correction is important because confocal microscopy is characterized by low signal to noise ratio. An intact (not corrected) background can reach up to $30 \%$ of the maximal fluorescence intensity and cause $30 \%$ of false positive colocalization (Landmann, 2004).

In summary, the results corroborate that uptake of positive as well as neutral NPs into M cells mainly occurs via CME and less via CvME, confirming the results obtained via flow cytometry and confocal microscopy.

\section{Conclusions}

The current study shows that size and surface chemistry play a crucial role in cytotoxic interactions and cellular uptake of NPs. Regarding the villous epithelium (enterocytes, goblet cells), which is entirely covered with mucus, $200 \mathrm{~nm}$ particles interact, independent on their surface charges, with intestinal mucoglycoproteins being immobilized and, as a consequence, cleared from the body. Regarding the FAE, we observed that uptake of NPs predominantly occurs via M cells due to higher adhesion capability, an enhanced elasticity of the cell membrane and a thinner or absent mucus layer. Negatively charged particles failed to enter M cells. In contrast, positively charged NPs as well as neutral particles were internalized via active transport mechanisms, more precisely, via CME and CVME.

\section{References}

Taken together, the presented data suggest that although the mucus layer is thinner compared with in vivo conditions, the intestinal in vitro models are appropriate to study interactions as well as transport mechanisms within the small intestine on a fundamental basis. Hence, the presented model can be used as an evaluation tool to assess safety aspects of manufactured nanomaterials. In addition, further tests will be performed using standard operating procedures (e.g., OECDtesting guidelines as recommended by NANoREG-project) (OECD) evaluating various manufactured nanomaterials (considering the physicochemical properties). These data will then be processed into ISA-TAB-nano-templates (ref. to eNanoMapper, NanoSafetyCluster-Modelling-projects), used for data modeling, grouping, risk categorization, and cross reading. It can be concluded that by this future outlook, the presented study substantially contributes to the nanosafety efforts to proactively show evidence of manufactured nanomaterials safety.

\section{Acknowledgements}

The authors thank Jennifer Ober of the Medical University of Graz, Center for Medical Research for her assistance with flow cytometry analysis and Susanne Resch for her assistance with cell culture studies.

\section{Declaration of interest}

The authors report no conflict of interest. The authors alone are responsible for the content and writing of the paper.
Antunes, F., Andrade, F., Araujo, F., Ferreira, D. and Sarmento, B. (2013). "Establishment of a triple co-culture in vitro cell models to study intestinal absorption of peptide drugs." Eur $J$ Pharm Biopharm 83(3): 427-435.

Barlow, A. L., Macleod, A., Noppen, S., Sanderson, J. and Guerin, C. J. (2010). "Colocalization analysis in fluorescence micrographs: verification of a more accurate calculation of pearson's correlation coefficient." Microsc Microanal 16(6): 710-724.

Behrens, I., Pena, A. I., Alonso, M. J. and Kissel, T. (2002). "Comparative uptake studies of bioadhesive and non-bioadhesive nanoparticles in human intestinal cell lines and rats: the effect of mucus on particle adsorption and transport." Pharm Res 19(8): 1185-1193.
Canton, I. and Battaglia, G. (2012). "Endocytosis at the nanoscale." Chem Soc Rev 41(7): 2718-2739.

Carney, R. P., Carney, T. M., Mueller, M. and Stellacci, F. (2012). "Dynamic cellular uptake of mixed-monolayer protected nanoparticles." Biointerphases 7(1-4): 17.

Conner, S. D. and Schmid, S. L. (2003). "Regulated portals of entry into the cell." Nature 422(6927): 37-44.

Crater, J. S. and Carrier, R. L. (2010). "Barrier properties of gastrointestinal mucus to nanoparticle transport." Macromol Biosci 10(12): 1473-1483.

des Rieux, A., Fievez, V., Theate, I., Mast, J., Preat, V. and Schneider, Y. J. (2007). "An improved in vitro model of human intestinal follicle-associated epithelium to study nanoparticle transport by $\mathrm{M}$ cells." Eur $J$ Pharm Sci 30(5): 380-391.

des Rieux, A., Ragnarsson, E. G., Gullberg, E., Preat, V., Schneider, Y. J. and Artursson, P. (2005). "Transport of nanoparticles across an in vitro model of the human intestinal follicle associated epithelium." Eur J Pharm Sci 25(4-5): 455465.

Doherty, G. J. and McMahon, H. T. (2009). "Mechanisms of endocytosis." Annu Rev Biochem 78: 857-902.

Froehlich, E. and Roblegg, E. (2014). "Mucus as barrier for drug delivery by nanoparticles." J Nanosci Nanotechnol 14(1): 126-136.

Fröhlich, E., Meindl, C., Roblegg, E., Griesbacher, A. and Pieber, T. R. (2012). 
"Cytotoxity of nanoparticles is influenced by size, proliferation and embryonic origin of the cells used for testing." Nanotoxicology 6(4): 424-439.

Goldberg, D. S., Ghandehari, H. and Swaan, P. W. (2010). "Cellular entry of G3.5 poly (amido amine) dendrimers by clathrinand dynamin-dependent endocytosis promotes tight junctional opening in intestinal epithelia." Pharm Res 27(8): 1547-1557.

Gullberg, E., Leonard, M., Karlsson, J., Hopkins, A. M., Brayden, D., Baird, A. W. and Artursson, P. (2000). "Expression of specific markers and particle transport in a new human intestinal M-cell model." Biochem Biophys Res Commun 279(3): 808-813.

Harush-Frenkel, O., Debotton, N., Benita, S. and Altschuler, Y. (2007). "Targeting of nanoparticles to the clathrin-mediated endocytic pathway." Biochem Biophys Res Commun 353(1): 26-32.

Harush-Frenkel, O., Rozentur, E., Benita, S. and Altschuler, Y. (2008). "Surface charge of nanoparticles determines their endocytic and transcytotic pathway in polarized MDCK cells." Biomacromolecules 9(2): 435-443.

He, B., Lin, P., Jia, Z., Du, W., Qu, W., Yuan, L., Dai, W., Zhang, H., Wang, X. and Wang, J. (2013). "The transport mechanisms of polymer nanoparticles in Caco-2 epithelial cells." Biomaterials 34(25): 6082-6098.

Herd, H., Daum, N., Jones, A. T., Huwer, H., Ghandehari, H. and Lehr, C. M. (2013). "Nanoparticle geometry and surface orientation influence mode of cellular uptake." ACS Nano 7(3): 1961-1973.

Hillaireau, H. and Couvreur, P. (2009). "Nanocarriers' entry into the cell: relevance to drug delivery." Cell Mol Life Sci 66(17): 2873-2896.

Huang, M., Ma, Z., Khor, E. and Lim, L. Y. (2002). "Uptake of FITC-chitosan nanoparticles by $\mathrm{A} 549$ cells." Pharm Res 19(10): 1488-1494.

Hubbard, S. R. and Till, J. H. (2000). "Protein tyrosine kinase structure and function." Annu Rev Biochem 69: 373-398.

Jang, M. H., Kweon, M. N., Iwatani, K., Yamamoto, M., Terahara, K., Sasakawa, C., Suzuki, T., Nochi, T., Yokota, Y., Rennert, P. D., Hiroi, T., Tamagawa, H., lijima, H.,
Kunisawa, J., Yuki, Y. and Kiyono, H. (2004). "Intestinal villous $\mathrm{M}$ cells: an antigen entry site in the mucosal epithelium." Proc Natl Acad Sci U S A 101(16): 6110-6115.

Keegan, M. E., Whittum-Hudson, J. A. and Saltzman, W. M. (2003). "Biomimetic design in microparticulate vaccines." Biomaterials 24(24): 4435-4443.

Keita, A. V., Soderholm, J. D. and Ericson, A. C. (2010). "Stress-induced barrier disruption of rat follicle-associated epithelium involves corticotropin-releasing hormone, acetylcholine, substance $\mathrm{P}$, and mast cells." Neurogastroenterol Motil 22(7): 770-778, e221-772.

Kerneis, S., Bogdanova, A., Kraehenbuhl, J. P. and Pringault, E. (1997). "Conversion by Peyer's patch lymphocytes of human enterocytes into $M$ cells that transport bacteria." Science 277(5328): 949-952.

Kerneis, S., Caliot, E., Stubbe, H., Bogdanova, A., Kraehenbuhl, J. and Pringault, E. (2000). "Molecular studies of the intestinal mucosal barrier physiopathology using cocultures of epithelial and immune cells: a technical update." Microbes Infect 2(9): 1119-1124.

Kirchhausen, T. (2000). "Clathrin." Annu Rev Biochem 69: 699-727.

Landmann, L. and Marbet, P. (2004). "Colocalization analysis yields superior results after image restoration." Microsc Res Tech 64(2): 103-112.

Lesuffleur, T., Porchet, N., Aubert, J. P., Swallow, D., Gum, J. R., Kim, Y. S., Real, F. X. and Zweibaum, A. (1993). "Differential expression of the human mucin genes MUC1 to MUC5 in relation to growth and differentiation of different mucus-secreting HT-29 cell subpopulations." J Cell Sci 106 ( Pt 3): 771-783.

Lewinski, N., Colvin, V. and Drezek, R. (2008). "Cytotoxicity of nanoparticles." small 4(1): 26-49.

Macia, E., Ehrlich, M., Massol, R., Boucrot, E., Brunner, C. and Kirchhausen, T. (2006). "Dynasore, a cell-permeable inhibitor of dynamin." Dev Cell 10(6): 839-850.

Mahler, G. J., Esch, M. B., Tako, E., Southard, T. L., Archer, S. D., Glahn, R. P. and Shuler, M. L. (2012). "Oral exposure to polystyrene nanoparticles affects iron absorption." Nat Nanotechnol 7(4): 264-271.

Manders, E., Verbeek, F. and Aten, J. (1993). "Measurement of co-localization of objects in dual-colour confocal images." Journal of microscopy 169(3): 375-382.

Mao, S., Germershaus, O., Fischer, D., Linn, T., Schnepf, R. and Kissel, T. (2005). "Uptake and transport of PEG-graft-trimethylchitosan copolymer-insulin nanocomplexes by epithelial cells." Pharm Res 22(12): 20582068.

Marks, D. L., Singh, R. D., Choudhury, A., Wheatley, C. L. and Pagano, R. E. (2005). "Use of fluorescent sphingolipid analogs to study lipid transport along the endocytic pathway." Methods 36(2): 186-195.

Mayer, A., Vadon, M., Rinner, B., Novak, A., Wintersteiger, R. and Fröhlich, E. (2009). "The role of nanoparticle size in hemocompatibility." Toxicology 258(2): 139147.

Nabi, I. R. and Le, P. U. (2003). "Caveolae/ raft-dependent endocytosis." J Cell Biol 161(4): 673-677.

Napierska, D., Thomassen, L. C., Rabolli, V., Lison, D., Gonzalez, L., KirschVolders, M., Martens, J. A. and Hoet, P. H. (2009). "Size-Dependent Cytotoxicity of Monodisperse Silica Nanoparticles in Human Endothelial Cells." Small 5(7): 846-853.

Nicoletti, C. (2000). "Unsolved mysteries of intestinal M cells." Gut 47(5): 735-739.

OECD Guidelines for the Testing of Chemicals http://www.oecd-ilibrary.org/ content/package/chem_guide_pkg-en

Park, M. V., Neigh, A. M., Vermeulen, J. P., de la Fonteyne, L. J., Verharen, H. W., Briedé, J. J., van Loveren, $H$. and de Jong, W. H. (2011). "The effect of particle size on the cytotoxicity, inflammation, developmental toxicity and genotoxicity of silver nanoparticles." Biomaterials 32(36): 9810-9817.

Parton, R. G., Joggerst, B. and Simons, K. (1994). "Regulated internalization of caveolae." J Cell Biol 127(5): 1199-1215.

Pelkmans, L., Kartenbeck, J. and Helenius, A. (2001). "Caveolar endocytosis of simian virus 40 reveals a new two-step vesicular-transport pathway to the ER." Nat Cell Biol 3(5): 473-483. 
Pietiainen, V., Marjomaki, V., Upla, P., Pelkmans, L., Helenius, A. and Hyypia, T. (2004). "Echovirus 1 endocytosis into caveosomes requires lipid rafts, dynamin II, and signaling events." Mol Biol Cell 15(11): 4911-4925.

Porter, A. E., Gass, M., Muller, K., Skepper, J. N., Midgley, P. and Welland, M. (2007). "Visualizing the uptake of C60 to the cytoplasm and nucleus of human monocytederived macrophage cells using energyfiltered transmission electron microscopy and electron tomography." Environ Sci Technol 41(8): 3012-3017.

Rappoport, J. Z. (2008). "Focusing on clathrin-mediated endocytosis." Biochem $J$ 412(3): 415-423.

Rejman, J., Oberle, V., Zuhorn, I. S. and Hoekstra, D. (2004). "Size-dependent internalization of particles via the pathways of clathrin- and caveolae-mediated endocytosis." Biochem J 377(Pt 1): 159169.

Roesslein, M., Elliott, J. T., Salit, M. L., Petersen, E. J., Hirsch, C., Krug, H. F. and Wick, P. (2014). "The use of cause-andeffect analysis to design a high quality nano- cytotoxicology assay." Chemical research in toxicology.

Sahay, G., Alakhova, D. Y. and Kabanov, A. V. (2010). "Endocytosis of nanomedicines." J Control Release 145(3): 182-195.

Schimpel, C., Teubl, B., Absenger, M., Meindl, C., Froehlich, E., Leitinger, G., Zimmer, A. and Roblegg, E. (2014). "Development of an advanced intestinal in vitro triple culture permeability model to study transport of nanoparticles." Mol Pharm 11(3): 808-818.

Schimpel, C., Werzer, O., Fröhlich, E., Leitinger, G., Absenger-Novak, M., Teubl, B., Zimmer, A. and Roblegg, E. (2015). "Atomic force microscopy as analytical tool to study physico-mechanical properties of intestinal cells." Beilstein J Nanotechnol 6: 1457-1466.

Sigurdsson, H. H., Kirch, J. and Lehr, C. M. (2013). "Mucus as a barrier to lipophilic drugs." Int J Pharm 453(1): 56-64.

Takei, K. and Haucke, V. (2001). "Clathrinmediated endocytosis: membrane factors pull the trigger." Trends Cell Biol 11(9): 385391.

Teubl, B. J., Meindl, C., Eitzlmayr, A., Zimmer, A., Fröhlich, E. and Roblegg, E.
(2013). "In-Vitro Permeability of Neutral Polystyrene Particles via Buccal Mucosa." Small 9(3): 457-466.

Vercauteren, D., Vandenbroucke, R. E., Jones, A. T., Rejman, J., Demeester, J., De Smedt, S. C., Sanders, N. N. and Braeckmans, K. (2010). "The use of inhibitors to study endocytic pathways of gene carriers: optimization and pitfalls." $\mathrm{Mol}$ Ther 18(3): 561-569.

Verma, A. and Stellacci, F. (2010). "Effect of surface properties on nanoparticle-cell interactions." Small 6(1): 12-21.

Wang, L. H., Rothberg, K. G. and Anderson, R. G. (1993). "Mis-assembly of clathrin lattices on endosomes reveals a regulatory switch for coated pit formation." $J$ Cell Biol 123(5): 1107-1117.

Zauner, W., Farrow, N. A. and Haines, A. M. (2001). "In vitro uptake of polystyrene microspheres: effect of particle size, cell line and cell density." J Control Release 71(1): 39-51.

Zinchuk, V. and Zinchuk, O. (2008). "Quantitative colocalization analysis of confocal fluorescence microscopy images." Curr Protoc Cell Biol Chapter 4: Unit 419. 